\title{
Gas chromatographic-mass spectrometric analysis of sunscreens and their effects on mice liver and kidney enzyme function
}

This article was published in the following Dove Medical Press journal: Clinical, Cosmetic and Investigational Dermatology

\author{
Laith N AL-Eitan ${ }^{1,2}$ \\ Hanan A Aljamal' \\ Rami Q Alkhatib 1,2 \\ 'Department of Applied Biological \\ Sciences, Jordan University of Science \\ and Technology, Irbid 221 10, Jordan; \\ ${ }^{2}$ Department of Biotechnology and \\ Genetic Engineering, Jordan University \\ of Science and Technology, Irbid \\ 22110 , Jordan
}

Background: Sunscreens are one of the most widely used products among cosmetics and personal care products. Recent studies have shown that some of sunscreen formulations may contain toxic, carcinogenic, or even nonallowed chemicals that may affect skin, cells, and hormones.

Materials and methods: This study aimed to develop and validate a method that allows the determination of sunscreen ingredients by gas chromatography-mass spectrometry (GC-MS). Analysis of original sunscreen products $(n=5)$ from a licensed pharmacy and counterfeit sunscreen products $(n=5)$ from local markets in Jordan was performed using GC-MS. pH stability of the sunscreen samples were also monitored under different storage temperatures. Topical application of sunscreens on mice skin was conducted to study their effects on liver and kidney enzymes' function. Results: In terms of $\mathrm{pH}$ stability, there is a significant change in $\mathrm{pH}$ at different degrees of temperature between the products. Diethyl phthalate (DEP) was detected in two counterfeit products and was not mentioned on the ingredients' label. DEP was reported for its percutaneous absorption and systemic uptake in the literature. Alanine aminotransferase (ALT) and aspartate aminotransferase (AST) were significantly increased with a $P<0.005$ in some groups treated with original sunscreens under sun radiation. Creatinine showed a significant decrease in some groups treated with original and counterfeit sunscreens, while blood urea nitrogen (BUN) showed no differences.

Conclusion: This study presents a method that allows the scanning and profiling of sunscreen ingredients as well as investigates their stability, permeation, and toxicity. Profiling of sunscreen product, changing in $\mathrm{pH}$ stability, and analyzing kidney and liver enzymes' level would be of a great impact on products' safety and consumers' health.

Keywords: skin absorption, sunscreening agents, aspartate aminotransferases, alanine transaminase, cosmetics, urea

\section{Introduction}

Sunscreen products could be defined as "any cosmetic product containing ultraviolet (UV) filters in its formulation in order to protect the skin from the solar deleterious UV light, avoiding and minimizing the damage that this radiation might cause on human health". ${ }^{1}$ To provide protection against these harmful effects, sunscreens are becoming widely spread and available for daily use.

Based on animal studies, sunscreen products help in preventing changes in dermis layer such as collagen degradation and solar elastosis, ${ }^{2}$ while, in human studies, sunscreens have been shown to reduce the severity of solar elastosis and the occurrence of squamous cell carcinoma, actinic cell carcinoma, and basal cell carcinoma. ${ }^{3-6}$ Protection
Correspondence: Laith N AL-Eitan Department of Applied Biological

Sciences, Jordan University of Science and Technology, PO Box 3030, Irbid 22I I0, Jordan

Tel +96227201000 ext 23464

Fax+96227201071

Email Ineitan@just.edu.jo 
quality of sunscreen is evolved by a formulation of chemical and physical filters. Chemical filters are also known as organic blockers, such as salicylates, para-aminobenzoic acid (PABA) derivatives, benzophenones, and dibenzoylmethanes. These filters act by absorbing the UV radiation (UVR) and transforming it into heat energy. ${ }^{7}$ This explains the feeling of warmth after applying the sunscreen and being exposed to sunlight. ${ }^{8}$ The other types of filters are physical or known as inorganic blockers, which act by scattering and reflecting UVR. ${ }^{9,10}$ These physical filters include metal oxides (titanium dioxide $\left[\mathrm{TiO}_{2}\right]$, zinc oxide $[\mathrm{ZnO}]$, and iron oxide), kaolin, and ichthammol. ${ }^{11}$

In addition to the protective function of sunscreens, there are important observations from previous studies on the possible side effects of UV filters in sunscreen formulation. ${ }^{12}$ Most commonly used chemical filters in sunscreen are homosalate, octisalate, avobenzone, octocrylene, octinoxate, and oxybenzone. Several studies indicate that these chemical filters mimic hormones and disrupt testosterone, estrogen, and thyroid pathways. ${ }^{13,14}$ In addition, they can penetrate skin causing allergy. ${ }^{15}$ Physical filters, such as $\mathrm{TiO}_{2}$ and $\mathrm{ZnO}$, stimulate oxidative damage in vitro and in cultured human fibroblasts. ${ }^{16}$ In contrast, several studies revealed that some of the sunscreen chemicals are inoffensive unless they are excited by sunlight. Such chemicals are padimate $\mathrm{O}$ inducing DNA damage and mutations, padimate esters, which induced tumor formation in hairless mice, and $\mathrm{TiO}_{2}$ that produced ROS and free radicals. ${ }^{17-19}$ Toxic effects of sunscreen products could be maintained and studied. Toxicology defined as "the study of the adverse effects of chemicals or physical agents on living organisms". ${ }^{20}$ These adverse effects can be ranging from immediate death to unrealizable changes until months or years later. They may occur at different levels within the body, such as a specific organ, a group of cells, and a certain type of biochemicals. ${ }^{21}$ This varies depending mainly on the dosage and route of exposure. There are different routes of exposure, either to a single chemical or to a combination of different chemicals; these routes include oral, inhalation, dermal, and parenteral. In terms of dermal exposure, toxicity can occur due to occupational agents, some water pollutants, or cosmetics. ${ }^{21}$

In our study, toxicity of sunscreen products at biochemical level was examined by analyzing some of the kidney and liver enzymes' function. Aspartate aminotransferase (AST) and alanine aminotransferase (ALT) enzymes are found throughout the body cells but mostly abundant in liver cells. They function to monitor liver disease or damage. Their elevation in blood is a useful indication for liver injury. ${ }^{22,23}$ Creatinine and blood urea nitrogen (BUN) are used along with each other to evaluate kidney function and diagnose kidney disease. ${ }^{24}$ Screening of sunscreen ingredients was conducted to evaluate the differences in sunscreen formulations from Jordanian pharmacies and local markets by scanning and profiling a group of original (ie, validated and verified products with internationally recognized brand names) and counterfeit sunscreen products (ie, fake and unauthorized replicate of the original ones). Various techniques have been developed and used for the detection and identification of sunscreen ingredients. Most of the used were chromatographic techniques such as gas chromatography (GC) coupled with mass spectrometry (MS).

In this study, we aimed to determine the safety of counterfeit products (CPs) obtained from local markets in Jordan by evaluating their stability, integrity, and toxicity through GC-MS profiling and enzymes' function analysis.

\section{Materials and methods Sunscreen samples}

Ten samples of sunscreen products were used in this study. Five of them were original products (OPs) supplied from a licensed Jordanian pharmacy, while the other five products were CPs obtained from local Jordanian market.

\section{GC-MS sample preparation}

For GC-MS analysis, samples first must be extracted in order to get a homogenized solution of each sunscreen product. A total of $0.5 \mathrm{~g}(500 \mathrm{mg})$ of the sunscreen was mixed with $5 \mathrm{~mL}$ of methanol in a $10 \mathrm{~mL}$ screw tube, vortexed for around 30 seconds, and then sonicated for 20 minutes. After that, samples were centrifuged at 5,000 rpm for 15 minutes. A $1.5 \mathrm{~mL}$ vials were filled with homogenized solution. Injection was made in splitless mode with $1 \mu \mathrm{L}$ of samples injected into the GC instrument.

\section{$\mathrm{pH}$ measurement}

Sunscreen samples were stored at different temperature degrees represented in Figure 1. At each measurement time, $1 \mathrm{~g}$ of each sample was homogenized in $10 \mathrm{~mL}$ of distilled water. $\mathrm{PH}$ meter was calibrated with the calibration solution at $\mathrm{pH} 7$ and $\mathrm{pH} 4$ before reading. Measurements were taken at different periods of time started at 0 hours of storage and, then, taken after 12 hours, 24 hours, 48 hours, 72 hours, 7 days, 14 days, and 21 days, and the final readings were taken after 28 days of storage. 


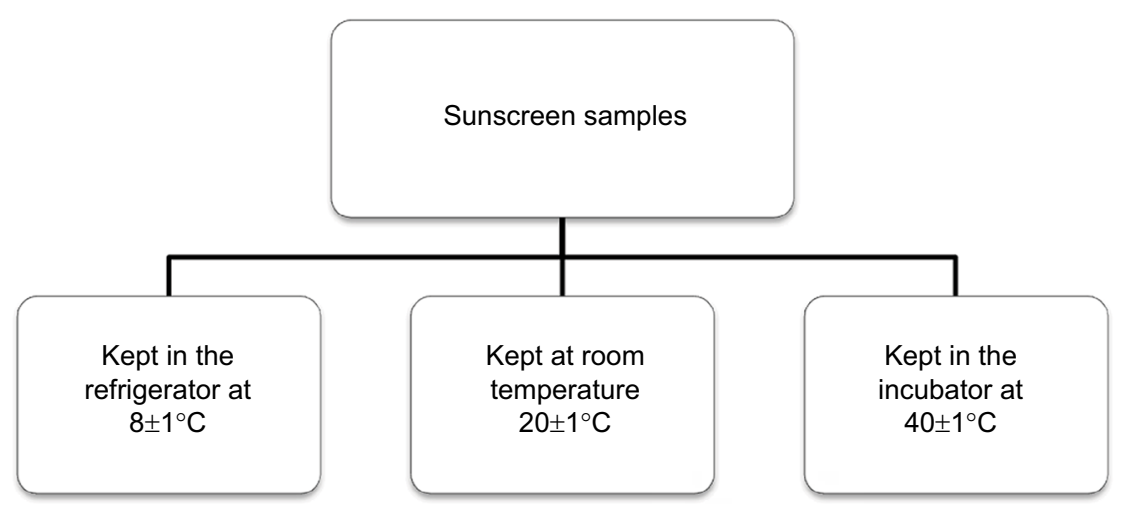

Figure I Flowchart represents the tested groups for $\mathrm{pH}$ stability under different storage temperatures.

\section{Animal and experimental design}

Two hundred bulb/C mice of both sexes were used in this study. They were provided by the Animal House Unite at the Jordan University of Sciences and Technology, Irbid, Jordan, in compliance with Animal Care and Use Committee (ACUC) approval, which follows the international animal care and use guidelines (Guide for the Care and Use of Laboratory Animals). ${ }^{25}$ Mice were maintained at the room temperature of $21 \pm 1^{\circ} \mathrm{C}$. Food and tap water of around $5 \mathrm{~g}$ and $6 \mathrm{~mL}$, respectively, of daily consumption were offered to them, and they were monitored for 2 weeks as adaptation period. Mice were divided into control and treated groups. Control groups contained 40 mice treated with normal saline on their skin. After that, 20 of them were exposed to sun radiation while the other 20 were kept under shade. For the treated groups, each single group was consisted of eight mice. We had 160 mice treated either with counterfeit sunscreen products or with original sunscreen products on their skin daily for 90 days as a long-term treatment by the application of $0.5 \mathrm{~mL}$ of each sunscreen. A total of 80 of them were being exposed to sun radiation, while the other 80 mice were kept under shade. After applying the sunscreen, mice were kept for 20 minutes before exposed to sun radiation according to the instructions of use. Time of exposure was gradually increased, starting with 10 minutes and end up with 2 hours. Exposure period was between 11:00 am and 1:00 pm during summer time. When the exposure period ended, mice were returned back to their room and sunscreen was removed off with a wet piece of cotton. Without removing sunscreen, a thick greasy layer formed on the treated skin. Mice were observed and checked daily for any changes through the entire experiment.

\section{Blood collection}

After euthanasia, blood samples were collected in plain tubes and then centrifuged at 1,300 rpm for 7 minutes to obtain serum for biochemical analysis.

\section{Biochemical tests}

Serum was analyzed by spectrophotometer for ALT (International Federation of Clinical Chemistry method), ${ }^{26}$ AST (International Federation of Clinical Chemistry method), ${ }^{27}$ creatinine (kinetic method), and BUN (colorimetric method) using commercially available kits and reagents according to the manufactures' recommendations.

\section{Statistical analysis}

Data were subjected to analyses using SPSS Version 19.0 statistics program with $P<0.05$ considered to be statistically significant, and they were expressed as mean \pm SD.

\section{Results $\mathrm{pH}$ stability}

Monitoring the $\mathrm{pH}$ value of sunscreen products is crucial for determining their stability. This is due to a fact that $\mathrm{pH}$ changes indicate the occurrence of chemical reactions and changes in some ingredients. ${ }^{28}$ As mentioned earlier, the $\mathrm{pH}$ range of human skin is $4.5-6$, which is slightly acidic. ${ }^{29,30}$ Products tested in this study had a $\mathrm{pH}$ range from 5.4 to 8.01 at different storage temperatures, which exceed the normal $\mathrm{pH}$ range of skin. OP1 is the only product that has a $\mathrm{pH}$ value within the normal $\mathrm{pH}$ range of skin, while $\mathrm{CP} 2$ has the highest $\mathrm{pH}$ range that was close to the basic $\mathrm{pH}$. Statistical analysis showed no significant difference within product in the same storage temperature at different measurement times (Table 1). 
Table I $P$-values of the $\mathrm{pH}$ measurements of sunscreen products at different degrees of temperatures for 28 days of storage

\begin{tabular}{|c|c|c|c|c|}
\hline \multirow[t]{3}{*}{ Product } & \multirow[t]{3}{*}{ Time } & \multicolumn{3}{|c|}{ Temperature } \\
\hline & & $8 \pm 1^{\circ} \mathrm{C}$ & $20 \pm 1^{\circ} \mathrm{C}$ & $40 \pm 1^{\circ} \mathrm{C}$ \\
\hline & & \multicolumn{3}{|l|}{$P$-value } \\
\hline OPI & \multirow{10}{*}{\begin{tabular}{|l}
0 hours \\
12 hours \\
48 hours \\
72 hours \\
7 days \\
14 days \\
21 days \\
28 days \\
28 days
\end{tabular}} & \multirow[t]{10}{*}{0.919} & \multirow[t]{10}{*}{0.913} & \multirow[t]{10}{*}{0.662} \\
\hline OP2 & & & & \\
\hline OP3 & & & & \\
\hline OP4 & & & & \\
\hline OP5 & & & & \\
\hline $\mathrm{CPI}$ & & & & \\
\hline $\mathrm{CP} 2$ & & & & \\
\hline CP3 & & & & \\
\hline CP4 & & & & \\
\hline CP5 & & & & \\
\hline
\end{tabular}

Notes: Within samples, each product in the same storage temperature at different measurement times.

Abbreviations: $\mathrm{CP}$, counterfeit product; $\mathrm{OP}$, original product.

On the other hand, there is a significant difference within the same product in different storage temperatures at the same time or at different times of measurement. Between samples, no changes observed when measurements taken at different storage conditions either at the same time or at different times. These data were applicable for both the OPs and CPs (Table 2).

\section{Qualitative analysis of sunscreen ingredients}

The original and counterfeit sunscreen samples were prepared as mentioned earlier followed by GC-MS analysis. Each ingredient was represented by a chromatogram peak, which identified by a number (Figures 2 and 3 and Table S5). Some peaks are large and repeated; these peaks usually represent a single ingredient available either in a high concentration or in a large size as what seen in peak number 15 and the other three peaks labeled with red in OP1 spectrum in Figure 2A. Sunscreens' ingredients list are provided in Table S1 according to the ingredients' label of each product with UV filters used in these products listed separately in Table S2 based on European Commission (Annex VI) database. Frequency of the GC-MS analyzed ingredients and their distribution between sunscreen products are shown in Table S3. Profiled ingredients that were not written on the ingredients' label of each product are listed in Table S4. Profiling was done for each obtained chemical by collecting their International Nomenclature of Cosmetic Ingredients (INCI) names, average retention time (RT), Chemical Abstracts Service (CAS) Registry Number, empirical formula, average molecular weight, synonymous, and chemical structure in Table S5. The uses of these analyzed ingredients were adopted from
Table $2 \mathrm{P}$-values of the $\mathrm{pH}$ measurements of sunscreen products at different temperatures for 28 days of storage

\begin{tabular}{|c|c|c|c|c|}
\hline \multirow[t]{3}{*}{ Product } & \multirow[t]{3}{*}{ Time } & \multicolumn{3}{|c|}{ Temperature } \\
\hline & & $8 \pm 1^{\circ} \mathrm{C}$ & $20 \pm 1^{\circ} \mathrm{C}$ & $40 \pm 1^{\circ} \mathrm{C}$ \\
\hline & & \multicolumn{3}{|l|}{$P$-value } \\
\hline OPI & \multirow{10}{*}{$\begin{array}{l}0 \text { hours } \\
12 \text { hours } \\
48 \text { hours } \\
72 \text { hours } \\
7 \text { days } \\
14 \text { days } \\
21 \text { days } \\
28 \text { days } \\
28 \text { days }\end{array}$} & \multirow[t]{10}{*}{$0.000^{*}$} & \multirow[t]{10}{*}{$0.000 *$} & \multirow[t]{10}{*}{$0.000 *$} \\
\hline OP2 & & & & \\
\hline OP3 & & & & \\
\hline OP4 & & & & \\
\hline OP5 & & & & \\
\hline $\mathrm{CPI}$ & & & & \\
\hline $\mathrm{CP} 2$ & & & & \\
\hline $\mathrm{CP3}$ & & & & \\
\hline $\mathrm{CP} 4$ & & & & \\
\hline$\overline{C P 5}$ & & & & \\
\hline
\end{tabular}

Notes: Between samples, in different storage temperatures at a single or different time. *Statistically significant at $P<0.05$.

Abbreviations: $\mathrm{CP}$, counterfeit product; $\mathrm{OP}$, original product.

the Cosmetic Ingredient Database, while the hazard score was adopted from the Environmental Working Group Cosmetic Database (Table S6). The hazard score key was ranged from 1 to 10 and classified into the following three groups: (1-2) group indicates a low hazard, (3-6) group indicates a moderate hazard, and (7-10) group indicates a high hazard.

\section{Biochemical markers}

ALT, AST, BUN, and creatinine levels were determined in all serum samples drawn from mice treated with original and counterfeit sunscreen products. Mice exposed to sun radiation daily for 90 days showed significant increase $(P<0.05)$ in ALT level in OP3, OP4, and OP5 and AST level in OP5. In addition, creatinine was significantly decreased in OP4, CP1, CP3, and CP5, while no changes were found in BUN level (Table 3). Treated mice that kept in shade for 90 days have shown significant decrease in creatinine level in OP1, OP4, OP5, and CP2. Moreover, mice treated with OP1 showed a significant increase in ALT level. AST was also significantly increased in mice treated with $\mathrm{OP} 4, \mathrm{CP} 1$, and $\mathrm{CP} 5$, while the mice treated with OP2 and CP5 showed an increase in BUN (Table 4). Liver-to-body weight ratio was also calculated after euthanasia and showed no significant changes in all groups (data not shown).

\section{Discussion}

Sunscreens are one of the most commonly used pharmaceuti$\mathrm{cal} /$ cosmetic products. Their use has increased recently due to the awareness of the deleterious effects during exposure to sun radiation, such as erythema, pigmentation, skin aging, skin cancers, and immunosuppression. ${ }^{31}$ Therefore, 
A

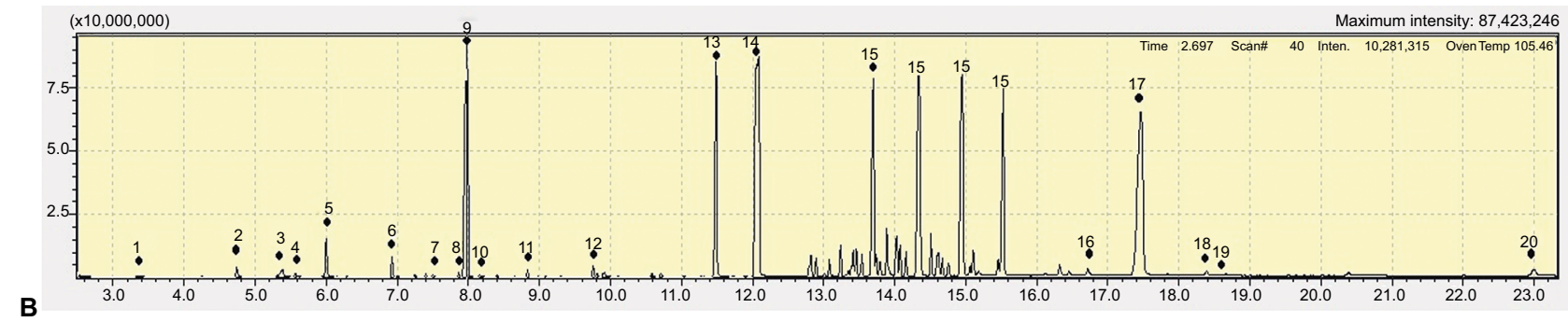

B

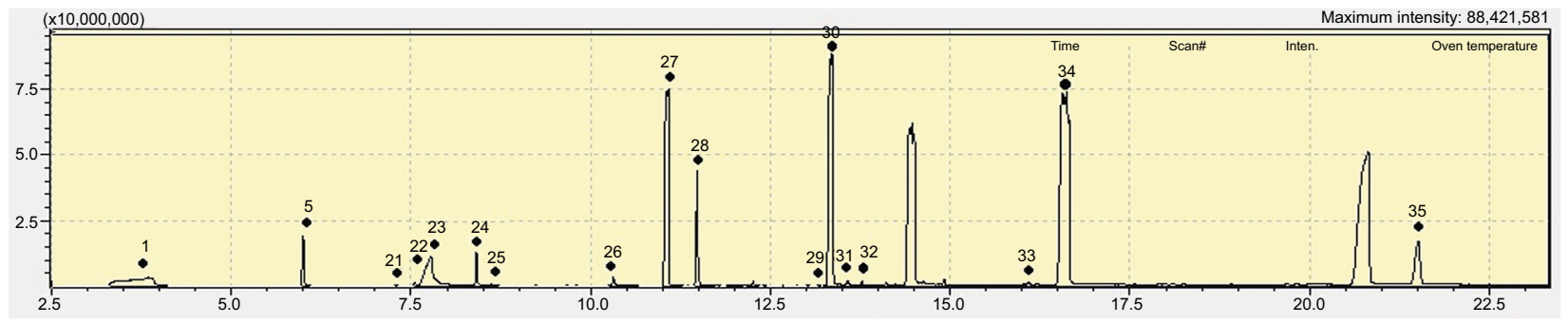

C

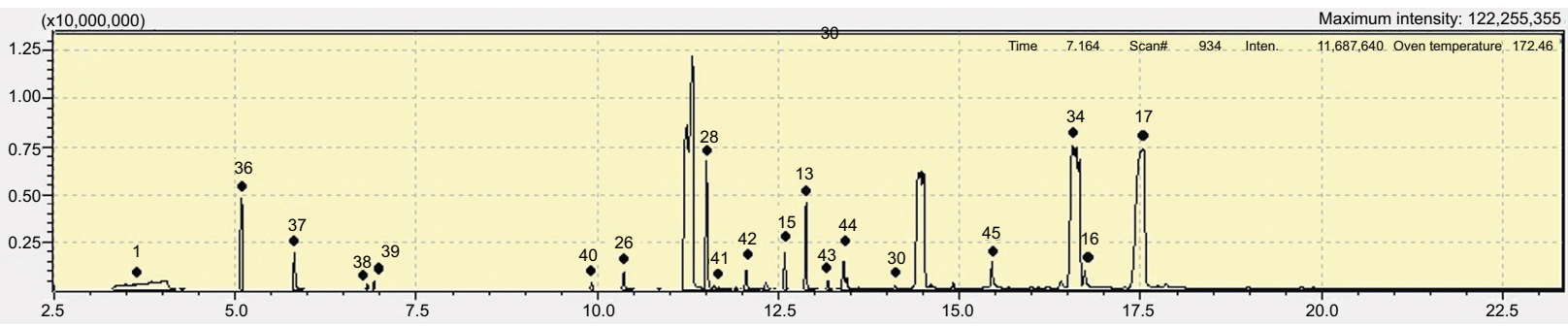

D
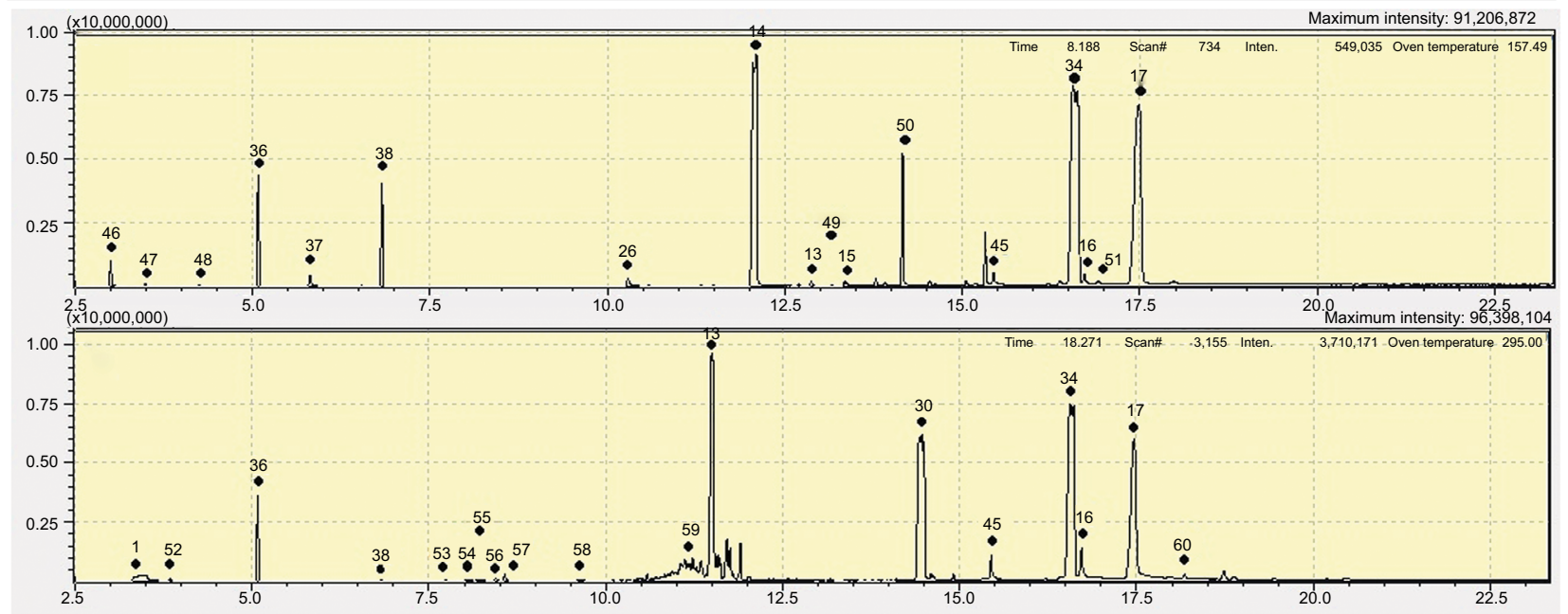

Figure 2 GC-MS chromatograms of the original sunscreen products.

Notes: (A) Original product I. (B) Original product 2. (C) Original product 3. (D) Original product 4. (E) Original product 5. Peaks' number was identified in Table S3. Abbreviation: GC-MS, gas chromatography-mass spectrometry.

protecting skin from the harmful UVR is highly recommended by cancer prevention organizations and health professionals. $\mathrm{pH}$ stability is one of the most important properties of sunscreen products. As $\mathrm{pH}$ is a measure of the hydrogen ion concentration, any change in the solution's temperature will be reflected by a subsequent change in $\mathrm{pH} .{ }^{32}$ This study shows that $\mathrm{pH}$ was not stable when measurements were taken at different storage temperature. Many factors could influence skin $\mathrm{pH}$ including both endogenous and exogenous elements. Cosmetic products are one of the exogenous factors that could affect the acid surface (acid mantel) of the skin. ${ }^{33}$ Barrier homeostasis, stratum corneum (SC) integrity, desquamation, cohesion, and antimicrobial defense are largely influenced by skin $\mathrm{pH} .{ }^{33}$ Increased skin 

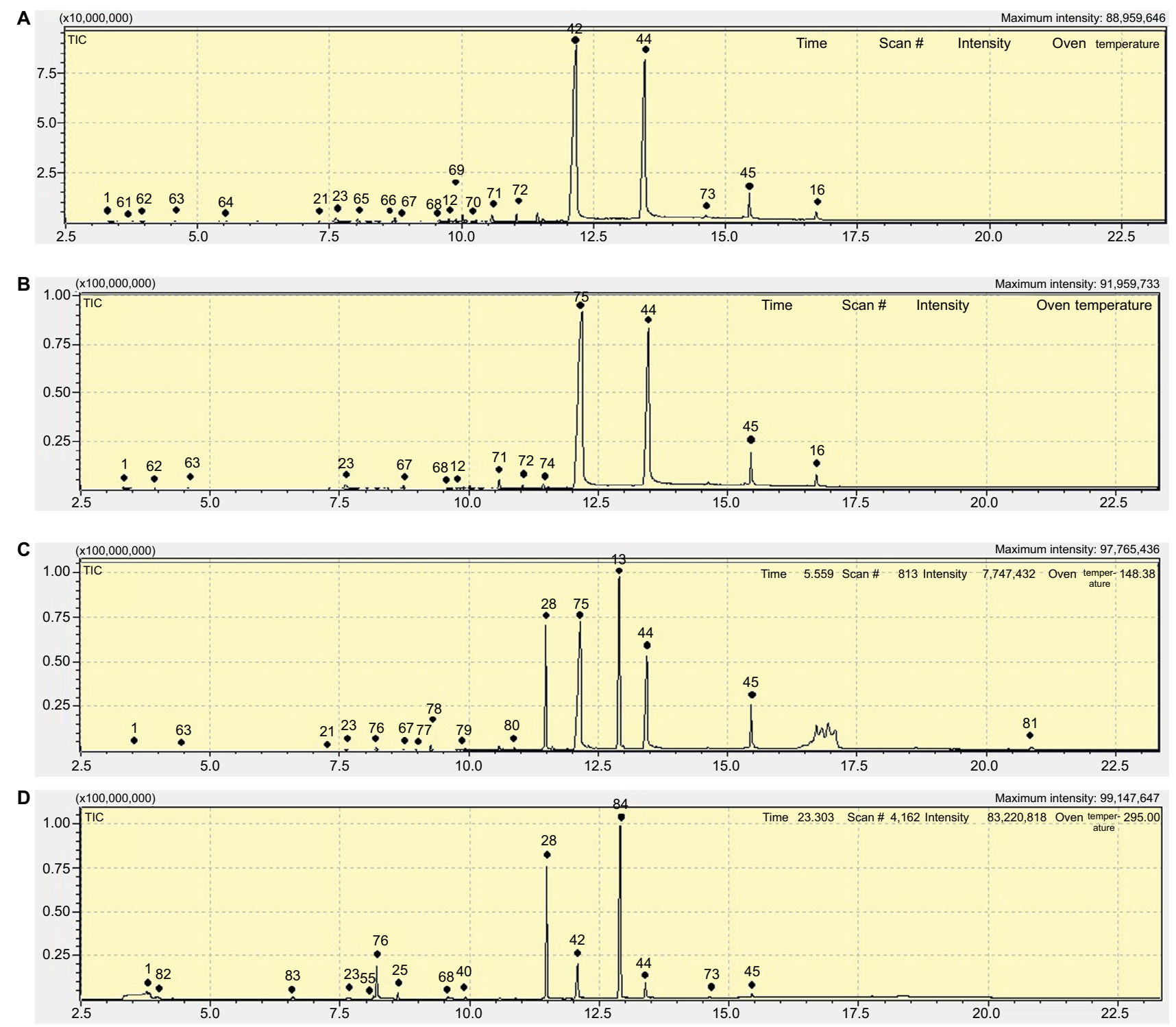

E

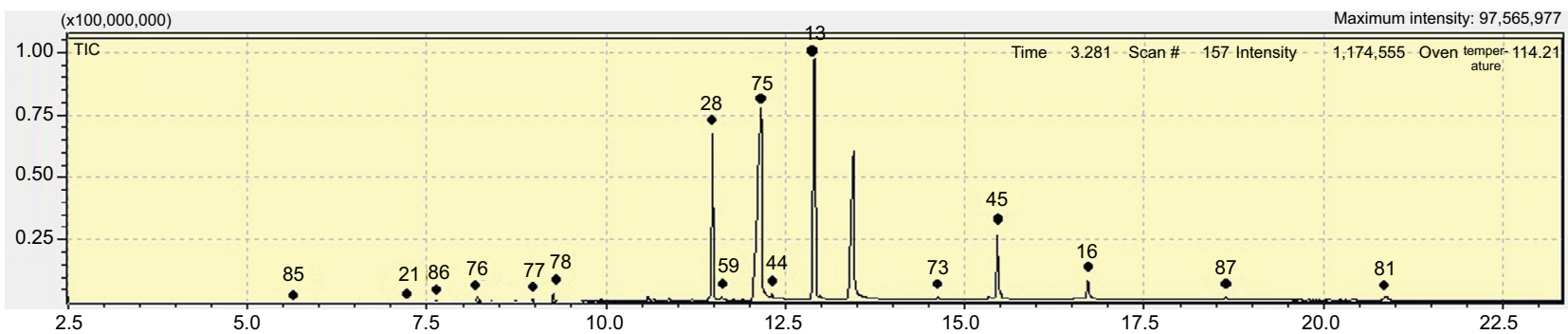

Figure 3 GC-MS chromatograms of the copied sunscreen products.

Notes: (A) Copied product I. (B) Copied product 2. (C) Copied product 3. (D) Copied product 4. (E) Copied product 5. Peaks' number was identified in Table S3. Abbreviation: GC-MS, gas chromatography-mass spectrometry.

$\mathrm{pH}$ may influence the activity of the enzymatic process in the SC leading to abnormality in permeability homeostasis, cohesion, and integrity of SC. ${ }^{33}$ A disturbed SC skin $\mathrm{pH}$ becomes clinically significant in several clinical situations such as in ichthyosis, acne and diaper, and atopic and irritant contact dermatitis. In addition, changes in skin $\mathrm{pH}$ are of clinical impact because of the creation of favorable growth environment for the bacteria, especially Staphylococcus aureus. ${ }^{34}$ Since the $\mathrm{pH}$ of skin is constant throughout the adulthood until the age of 70 years, ${ }^{35}$ the $\mathrm{pH}$ of sunscreens 
Table 3 Serum biochemical analysis for control, original, and copied sunscreen-treated groups under sun radiation

\begin{tabular}{|l|l|l|l|l|}
\hline Test product & ALT (U/L) & AST (U/L) & BUN (mg/dL) & Creatinine (mg/dL) \\
\hline Control & $45.33 \pm 14.60$ & $84.25 \pm 20.13$ & $21.583 \pm 6.417$ & $0.6333 \pm 0.3339$ \\
\hline OPI & $43.89 \pm 19.95$ & $83.33 \pm 37.01$ & $23.667 \pm 7.467$ & $0.5222 \pm 0.299 I$ \\
\hline OP2 & $64.13 \pm 29.66$ & $59.50 \pm 34.97$ & $18.375 \pm 5.902$ & $0.4625 \pm 0.2560$ \\
\hline OP3 & $76.7 I \pm 13.30^{*}$ & $51.86 \pm 47.02$ & $21.000 \pm 7.724$ & $0.5143 \pm 0.26 I 0$ \\
\hline OP4 & $78.50 \pm 15.40^{*}$ & $67.50 \pm 42.11$ & $22.167 \pm 7.223$ & $0.3333 \pm 0.1633^{*}$ \\
\hline OP5 & $63.63 \pm 20.30 *$ & $54.00 \pm 34.74 *$ & $20.625 \pm 5.95 I$ & $0.4875 \pm 0.2800$ \\
\hline CPI & $44.14 \pm 20.38$ & $58.57 \pm 37.50$ & $18.000 \pm 6.218$ & $0.407 I \pm 0.1880^{*}$ \\
\hline CP2 & $43.90 \pm 19.97$ & $76.80 \pm 24.61$ & $20.900 \pm 5.109$ & $0.5200 \pm 0.2898$ \\
\hline CP3 & $53.00 \pm 13.10$ & $76.25 \pm 22.78$ & $21.750 \pm 4.713$ & $0.3500 \pm 0.2204^{*}$ \\
\hline CP4 & $35.1 I \pm 15.64$ & $93.22 \pm 34.07$ & $22.111 \pm 6.566$ & $0.4667 \pm 0.2398$ \\
\hline CP5 & $39.56 \pm 21.984$ & $107.00 \pm 34.38$ & $19.000 \pm 5.701$ & $0.4000+0.2179 *$ \\
\hline
\end{tabular}

Notes: Values are presented as mean \pm SD. *Statistically significant at $P<0.05$.

Abbreviations: ALT, alanine aminotransferase; AST, aspartate aminotransferase; BUN, blood urea nitrogen; CP, counterfeit product; OP, original product.

Table 4 Serum biochemical analysis for original and copied sunscreen-treated groups under shade

\begin{tabular}{|c|c|c|c|c|}
\hline Test product & ALT (U/L) & AST (U/L) & BUN (mg/dL) & Creatinine $(\mathrm{mg} / \mathrm{dL})$ \\
\hline Control & $43.42 \pm 13.79$ & $78.67 \pm 16.58$ & $19.75 \pm 5.154$ & $0.5583 \pm 0.2778$ \\
\hline OPI & $56.33 \pm 15.65^{*}$ & $95.00 \pm 22.44$ & $22.11 \mathrm{I} \pm 8.594$ & $0.3111 \pm 0.1764^{*}$ \\
\hline OP2 & $52.75 \pm 17.40$ & $88.75 \pm 31.12$ & $26.125 \pm 5.357 *$ & $0.5625 \pm 0.2326$ \\
\hline OP3 & $48.00 \pm 10.10$ & $80.29 \pm 17.84$ & $23.429 \pm 5.533$ & $0.4143 \pm 0.2410$ \\
\hline OP4 & $40.50 \pm 16.91$ & $103.50 \pm 16.13^{*}$ & $23.500 \pm 6.047$ & $0.3875 \pm 0.1246 *$ \\
\hline OP5 & $45.22 \pm 11.97$ & $88.89 \pm 21.25$ & $20.778 \pm 7.612$ & $0.2667 \pm 0.1658 *$ \\
\hline $\mathrm{CPI}$ & $43.13 \pm 14.84$ & $113.88 \pm 17.36^{*}$ & $30.625 \pm 19.949$ & $0.4875 \pm 0.2900$ \\
\hline $\mathrm{CP} 2$ & $55.22 \pm 16.34$ & $109.22 \pm 44.46$ & $18.333 \pm 4.743$ & $0.2778 \pm 0.0833^{*}$ \\
\hline $\mathrm{CP3}$ & $45.00 \pm 19.09$ & $100.13 \pm 37.85$ & $22.375 \pm 10.980$ & $0.4 I 25 \pm 0.203 \mathrm{I}$ \\
\hline $\mathrm{CP} 4$ & $53.14 \pm 15.98$ & $88.57 \pm 27.48$ & $22.000 \pm 6.055$ & $0.4000 \pm 0.1826$ \\
\hline CP5 & $44.56 \pm 10.25$ & $99.00 \pm 24.58 *$ & $23.889 \pm 4.649 *$ & $0.4444 \pm 0.1944$ \\
\hline
\end{tabular}

Notes: Values are presented as mean \pm SD. *Statistically significant at $P<0.05$.

Abbreviations: ALT, alanine aminotransferase; AST, aspartate aminotransferase; BUN, blood urea nitrogen; CP, counterfeit product; OP, original product.

that use in direct contact with skin should be stable to avoid any significant impacts on the skin.

Skin care products, especially sunscreens, are subjected to many toxicity studies investigating their safety and risk assessment. US Food and Drug Administration (FDA), European Committee (EC), Cosmetic Ingredient Review (CIR), and many other organizations have a leading role in controlling cosmetics and personal care products. Several studies have investigated the toxicity and safety of UV filters used in sunscreen formulations by different methods and models. The current study used 10 sunscreen products available in the Jordanian pharmacies and local markets. The analytical method used here was able to determine and qualify different sunscreen ingredients. Application of GC coupled with MS technique ensures a high level of specificity with no requirement of additional confirmatory techniques. Chemicals' profile obtained by GC-MS was compared with the ingredients' label of each product; two CPs have no ingredient label at all, and this raised a question about the role of Jordanian Standards and Metrology Organization in controlling such products in the Jordanian markets.

In this study, some chemicals obtained from the GC-MS analysis were not mentioned on the ingredients' label of the products. A group of these chemicals are used as fragrances such as butylphenyl methylpropional (lilial) that must be used under high restrictions according to the International Fragrance Association (IFRA) due to its potential sensitization. ${ }^{36}$ Butylphenyl methylpropional was found only in three CPs including CP1, CP2, and CP3. Penetration of fragrance compounds through human epidermis was reported by Jimbo $^{37}$ through examination of 18 fragrance materials including six phenolic compounds, four benzyl compounds, two salicylate compounds, and six cinnamic compounds. A total of $0.2 \mathrm{~mL}$ of each sample was applied to epidermis tis- 
sues kept in a thermostatically controlled cabinet for 72 hours. Of the 18 tested samples, penetration of benzyl alcohol into human epidermis was significantly rapid $(P<0.01)$, followed by eugenol, dihydro eugenol, and benzyl acetate. ${ }^{37}$ According to the EC regulation on cosmetic products, the presence of substances, such as benzyl alcohol and eugenol, is restricted and must be indicated in the list of ingredients when their concentration exceeds $0.001 \%$ in leave-on products and $0.01 \%$ in rinse-off products. ${ }^{38}$ In vitro study on the oestrogenic activity of three cosmetic ingredients used around human breast including butylphenyl methylpropional was conducted using MCF7 human breast cancer cell line as an estrogen responsive. They reported that these three cosmetic ingredients possess an oestrogenic response in a human breast cancer cell line in culture. ${ }^{39}$ Another group of these chemicals is used as a plasticizer such as dibutyl phthalate (DBP), which is also not mentioned on the ingredients' label of CP3 and CP5. In vivo study on human skin showed the evidence of percutaneous absorption of DBP estimated by $68 \mathrm{mg} / 1$ hour after treating the whole skin surface $\left(1.8 \mathrm{~m}^{2}\right)$ with a saturated solution. ${ }^{40}$ Another study on the systemic uptake of DBP detected its presence in the serum after a whole body topical application in healthy male volunteers. After examination, there was no influence observed on the levels of thyroid and reproductive hormones after systemic absorption of DBP. ${ }^{41}$ Propylparaben (PB), an antimicrobial preservative, is another ingredient obtained from GC analysis . In vitro study using human skin exhibited percutaneous absorption of six parabens commonly used in cosmetics formulations. They found that percutaneous absorption of parabens dissolved in an aqueous vehicle was increased in the SC with increasing lipophilicity of the formula and decreasing solubility in the vehicle. ${ }^{42} \mathrm{~A}$ whole body dermal application of $2 \mathrm{mg}$ cream $/ \mathrm{cm}^{2}$ containing $2 \%(\mathrm{w} / \mathrm{w})$ of diethyl phthalate (DEP), DBP and butyl paraben (BP) was detected in serum within 1 hour, showing a rapid skin penetration and systemic uptake in humans. ${ }^{41}$ These studies have shown evidence on the side effects of these ingredients. Percutaneous absorption and systemic uptake of such chemicals with prolonged term of use could eventually reach some vital organs, such as kidney and liver causing organ toxicity or injury. In this work, some UV filters obtained from the GC analysis are widely used in sunscreens such as octinoxate (octyl methoxy cinnamate [OMC]), which found in OP2, OP3, and OP5. A study on 82 outpatients with clinical diagnosis of photoallergic contact dermatitis attended a dermatology clinic in Colombia to identify the photoallergen agents. OMC was the second photoallergen causative in eight of the 82 cases showing positive photopatch in response to
OMC. ${ }^{43}$ Various in vitro and in vivo studies conducted in rodents reported the estrogenic activity of UV filters especially OMC. ${ }^{13,44}$ Rodents generally show higher permeation rates compared to human skin. However, they are most commonly practical models used in permeation and regulatory toxicity studies due to their structural similarities to human skin. ${ }^{45}$ A pharmacodynamic study in adult ovariectomized rats with five dosages of OMC was conducted to quantify its estrogenic properties. As a result, OMC considered as endocrine active chemical (EAC) with a recommendation to reduce its use in cosmetic and personal care products. ${ }^{44}$ Detection of OMC in the plasma and urine of healthy human volunteers assigned to daily whole body topical application of sunscreen indicating its ability of skin penetration and systemic uptake in humans. ${ }^{46}$ A study on healthy male and female volunteers exposed daily to whole body topical application of sunscreen formula containing three UV filters (oxybenzone [BP-3], $\mathrm{OMC}$, and 4-methylbenzylidene camphor [4-MBC]) for 4 days. These three UV filters were detected in the plasma and urine after 1-2 hours of first application. ${ }^{47}$ On the other hand, Scientific Committee for Cosmetic Products and NonFood Products (SCCNFP) concluded that UV filters used in sunscreen products in the European markets have no estrogenic effects that could potentially affect human health. ${ }^{48}$ Therefore, they permit the use of UV filters in sunscreen products regardless the reported side effects on some of these filters. Systemic absorption and penetration studies of topical application of many care products ingredients into human skin were reported. ${ }^{49-52}$ Thus, these ingredients could eventually circulate into the blood stream reaching some vital organs, such as liver and kidney. Several biomarkers can be tested to reveal liver and kidney injuries or damage. In the current study, analysis of AST, ALT, BUN, and creatinine was performed. Increased level of ALT and AST enzymes is usually a sign of liver damage or injury where they are abundant in the liver. Biochemical testing showed that creatinine is significantly decreased when compared to the control group in mice treated under shade with OP1, OP4, and OP5 and CP2. These obtained data proposed possible hyperfiltration of the kidneys or as indicative of systemic or localized problem of defective muscle metabolism. For ALT, it was significantly increased when compared with the control group in mice treated with OP3, OP4, and OP5 and exposed to sun radiation. Butyl methoxydibenzoylmethane (BMBM) and octocrylene UV filters are shared ingredients between these three products that found to be absorbed through the skin. ${ }^{36,53,54}$ An ex vivo study of five UV filter solutions including BMBM across baby mouse skin indicated that at $4.4 \mathrm{mg} /$ 
$\mathrm{cm}^{2}$ coverage of BMBM, $0.80 \pm 0.28 \%$ of the applied BMBM penetrate through the epidermis and dermis after 24 hours of application. Transepidermal penetration of BMBM through human epidermis was obvious in all five volunteers after 3 hours application of $2 \mathrm{mg}$ of BMBM, which agree with the mouse skin penetration results. ${ }^{53}$ Decamethylcyclopentasiloxane (D5) is another ingredient found only in these three products. The physical properties of D5, such as volatility, hydrophobicity, and low surface tension, make it attractive for use in various skin care products as volatile nongreasy carriers compatible with a wide range of different ingredients. Therefore, under normal conditions of use, the potential routes of human exposure to D5 are inhalation and dermal contact. ${ }^{55}$ Pharmacokinetic modeling of dermal absorption in human volunteers indicated that $0.05 \%$ of applied D5 was absorbed into systemic circulation in both men and women. ${ }^{56}$ Consistent with this result, around $90 \%$ of D5 were volatilized from the skin surface before being absorbed when applied to human skin in vitro and rat skin in vivo. ${ }^{55}$ Absorption and accumulation of these ingredients could injure the liver and results in the release of ALT into the blood stream, which could explain the elevated level of ALT in some of the treated mice. UV filters should possess a high substantivity with the least transdermal penetration to the systemic circulation. According to several studies, some UV filters could be absorbed into the body through topical application. ${ }^{57,58}$ Despite that some studies have raised concerns about the safety of sunscreen products, there is insufficient evidence to confirm that sunscreen ingredients have toxic effects on tissues. A better understanding of skin absorption, influence of formulation vehicles, distribution of clinically relevant doses, and toxicity studies in tissues is requiring for sunscreens' risk assessment.

\section{Conclusion}

Current study showed that counterfeit sunscreens' ingredients were differed from the original ones based on the GC-MS analysis. This study also revealed that some ingredients could influence the levels of kidney and liver enzymes. A change in $\mathrm{pH}$ stability of the products at different storage temperatures could be of a clinical impact on skin health and integrity. Improved studies and standardized methods must be developed into suitable protocols to help manufacturers in providing safer and more photostable products. In addition, in vivo and in vitro studies conducting on a group of sunscreens consumers here in Jordan with awareness raising of the choosing and using of sunscreen products will be beneficial to the society.

\section{Acknowledgment}

This work was supported by the Deanship of Research at Jordan University of Science and Technology under grant number (RN: 2014217).

\section{Disclosure}

The authors report no conflicts of interest in this work.

\section{References}

1. Pont AR, Charron AR, Brand RM. Active ingredients in sunscreens act as topical penetration enhancers for the herbicide 2,4-dichlorophenoxyacetic acid. Toxicol Appl Pharmacol. 2004;195(3):348-354.

2. Roelandts R. Shedding light on sunscreens. Clin Exp Dermatol. 1998;23(4):147-157.

3. Thompson SC, Jolley D, Marks R. Reduction of solar keratoses by regular sunscreen use. N Engl J Med. 1993;329(16):1147-1151.

4. Boyd AS, Naylor M, Cameron GS, Pearse AD, Gaskell SA, Neldner $\mathrm{KH}$. The effects of chronic sunscreen use on the histologic changes of dermatoheliosis. J Am Acad Dermatol. 1995;33(6):941-946.

5. Green A, Williams G, Neale R, et al. Daily sunscreen application and betacarotene supplementation in prevention of basal-cell and squamouscell carcinomas of the skin: a randomised controlled trial. Lancet. 1999;354(9180):723-729.

6. Darlington S, Williams G, Neale R, Frost C, Green A. A randomized controlled trial to assess sunscreen application and beta carotene supplementation in the prevention of solar keratoses. Arch Dermatol. 2003;139(4):451-455.

7. Bech-Thomsen N, Wulf HC. Sunbathers' application of sunscreen is probably inadequate to obtain the sun protection factor assigned to the preparation. Photodermatol Photoimmunol Photomed. 1993;9(6): $242-244$.

8. Draelos ZD. Compliance and sunscreens. Dermatol Clin. 2006;24(1):101-104.

9. Serpone N, Dondi D, Albini A. Inorganic and organic UV filters: Their role and efficacy in sunscreens and suncare products. Inorganica Chim Acta. 2007;360(3):794-802.

10. Koshy JC, Sharabi SE, Jerkins D, Cox J, Cronin SP, Hollier LH Jr. Sunscreens: evolving aspects of sun protection. J Pediatr Health Care. 2010;24(5):343-346.

11. Lowe NJ. An overview of ultraviolet radiation, sunscreens, and photoinduced dermatoses. Dermatol Clin. 2006;24(1):9-17.

12. Krause M, Klit A, Blomberg Jensen M, et al. Sunscreens: are they beneficial for health? An overview of endocrine disrupting properties of UV-filters. Int J Androl. 2012;35(3):424-436.

13. Schlumpf M, Cotton B, Conscience M, Haller V, Steinmann B, Lichtensteiger W. In vitro and in vivo estrogenicity of UV screens. Environ Health Perspect. 2001;109(3):239-244.

14. Schlumpf M, Schmid P, Durrer S, et al. Endocrine activity and developmental toxicity of cosmetic UV filters-an update. Toxicology. 2004;205(1-2):113-122.

15. Calafat AM, Wong LY, Ye X, Reidy JA, Needham LL. Concentrations of the sunscreen agent benzophenone-3 in residents of the United States: National Health and Nutrition Examination Survey 2003-2004. Environ Health Perspect. 2008;116(7):893-897.

16. Dunford R, Salinaro A, Cai L, et al. Chemical oxidation and DNA damage catalysed by inorganic sunscreen ingredients. FEBS Lett. 1997;418(1-2):87-90.

17. Knowland J, McKenzie EA, McHugh PJ, Cridland NA. Sunlightinduced mutagenicity of a common sunscreen ingredient. FEBS Lett. 1993;324(3):309-313.

18. Rampaul A, Parkin IP, Cramer LP. Damaging and protective properties of inorganic components of sunscreens applied to cultured human skin cells. J Photochem Photobiol A Chem. 2007;191(2-3):138-148. 
19. Mei N, Hu J, Xia Q, Fu PP, Moore MM, Chen T. Cytotoxicity and mutagenicity of retinol with ultraviolet A irradiation in mouse lymphoma cells. Toxicol In Vitro. 2010;24(2):439-444.

20. Klaassen CD, Watkins JB. Casarett \& Doull's Essentials of Toxicology. 3rd ed. New York: McGraw-Hill Medical; 2015.

21. Hayes AW, Kruger CL. Hayes' Principles and Methods of Toxicology. 6th ed. Boca Raton: CRC Press, Taylor and Francis Group; 2014.

22. Pagana KD, Pagana TG. Mosby's Manual of Diagnostic and Laboratory Tests. 4th ed. St. Louis, Mo.: Mosby/Elsevier; 2010.

23. Feldman M, Friedman LS, Brandt LJ. Sleisenger and Fordtran's Gastrointestinal and Liver Disease. 10th ed. Philadelphia, PA: Saunders/ Elsevier; 2016.

24. Skorecki K, Marsden PA, Chertow GM, et al. Brenner \& Rector's The Kidney. 10th ed. Philadelphia, PA: Elsevier Health Sciences; 2016.

25. Institute of Laboratory Animal Resources (ILAR). Guide for the Care and Use of Laboratory. Washington, DC: National Academy Press; 1996.

26. Bergmeyer HU, Horder M. IFCC Methods for the Measurement of Catalytic Concentration of Enzymes Part 3. IFCC Method for Alanine Aminotransferase. J Clin Chem Clin Biochem. 1980;18(8):521-534.

27. Bergmeyer HU, Bowers GN Jr, Hörder M, Moss DW. Provisional recommendations on IFCC methods for the measurement of catalytic concentrations of enzymes. Part 2. IFCC method for aspartate aminotransferase. Clin Chim Acta. 1976;70(2):F19-F42.

28. Some IT, Bogaerts P, Hanus R, Hanocq M, Dubois J. Improved kinetic parameter estimation in $\mathrm{pH}$-profile data treatment. Int $J$ Pharm. 2000;198(1):39-49.

29. Schirren CG. Does the glass electrode determine the same $\mathrm{pH}$-values on the skin surface as the quinhydrone electrode? J Invest Dermatol. 1955;24(5):485-488.

30. Zlotogorski A. Distribution of skin surface $\mathrm{pH}$ on the forehead and cheek of adults. Arch Dermatol Res. 1987;279(6):398-401.

31. Polefka TG, Meyer TA, Agin PP, Bianchini RJ. Effects of solar radiation on the skin. J Cosmet Dermatol. 2012;11(2):134-143.

32. Zumdahl SS, DeCoste DJ. Introductory Chemistry: A Foundation. 7th ed. Belmont, CA: Brooks/Cole, CENGAGE Learning; 2010.

33. Ali SM, Yosipovitch G. Skin $\mathrm{pH}$ : from basic science to basic skin care. Acta Derm Venereol. 2013;93(3):261-267.

34. Schmid-Wendtner MH, Korting HC. The $\mathrm{pH}$ of the skin surface and its impact on the barrier function. Skin Pharmacol Physiol. 2006;19(6):296-302.

35. Waller JM, Maibach HI. Age and skin structure and function, a quantitative approach (I): blood flow, $\mathrm{pH}$, thickness, and ultrasound echogenicity. Skin Res Technol. 2005;11(4):221-235.

36. Ewg.org. [homepage on the Internet]. Skin Deep ${ }^{\circledR}$ Cosmetics Database. EWG; 2016. Available from: http://www.ewg.org/skindeep/. Accessed March 16, 2016.

37. Jimbo Y. Penetration of fragrance compounds through human epidermis. J Dermatol. 1983;10(3):229-239.

38. EUR-LEX-32009R1223 [homepage on the Internet]. Regulation (EC) No 1223/2009 of the European parliament and of the council of 30 November 2009 on Cosmetic Products. Available from: https://eurlex.europa.eu/legal-content/EN/ALL/?uri=CELEX\%3A32009R1223. Accessed November 2, 2018.

39. Charles AK, Darbre PD. Oestrogenic activity of benzyl salicylate, benzyl benzoate and butylphenylmethylpropional (Lilial) in MCF7 human breast cancer cells in vitro. J Appl Toxicol. 2009;29(5):422-434.

40. Hagedorn-Leweke U, Lippold BC. Absorption of sunscreens and other compounds through human skin in vivo: derivation of a method to predict maximum fluxes. Pharm Res. 1995;12(9):1354-1360.
41. Janjua NR, Mortensen GK, Andersson AM, Kongshoj B, Skakkebaek NE, Wulf HC. Systemic uptake of diethyl phthalate, dibutyl phthalate, and butyl paraben following whole-body topical application and reproductive and thyroid hormone levels in humans. Environ Sci Technol. 2007;41(15):5564-5570.

42. Pozzo AD, Pastori N. Percutaneous absorption of parabens from cosmetic formulations. Int J Cosmet Sci. 1996;18(2):57-66.

43. Rodríguez E, Valbuena MC, Rey M, Porras de Quintana L. Causal agents of photoallergic contact dermatitis diagnosed in the national institute of dermatology of Colombia. Photodermatol Photoimmunol Photomed. 2006;22(4):189-192.

44. Klammer H, Schlecht C, Wuttke W, Jarry H. Multi-organic risk assessment of estrogenic properties of octyl-methoxycinnamate in vivo A 5-day sub-acute pharmacodynamic study with ovariectomized rats. Toxicology. 2005;215(1-2):90-96.

45. Jung EC, Maibach HI. Animal Models for Percutaneous Absorption in Topical Drug Bioavailability, Bioequivalence, and Penetration. New York, NY: Springer; 2014:21-40.

46. Janjua NR, Mogensen B, Andersson AM, et al. Systemic absorption of the sunscreens benzophenone-3, octyl-methoxycinnamate, and 3-(4-methyl-benzylidene) camphor after whole-body topical application and reproductive hormone levels in humans. J Invest Dermatol. 2004;123(1):57-61.

47. Janjua NR, Kongshoj B, Andersson AM, Wulf HC. Sunscreens in human plasma and urine after repeated whole-body topical application. $J$ Eur Acad Dermatol Venereol. 2008;22(4):456-461.

48. Ec.europa.eu. [homepage on the Internet]. CosIng - Cosmetics Health and Consumers - European Commission; 2016. Available from: http://ec.europa.eu/growth/tools-databases/cosing/index. cfm?fuseaction=search.simple. Accessed March 16, 2016.

49. Moss T, Howes D, Williams FM. Percutaneous penetration and dermal metabolism of triclosan (2,4, 4'-trichloro-2'-hydroxydiphenyl ether). Food Chem Toxicol. 2000;38(4):361-370.

50. Guillard O, Fauconneau B, Olichon D, Dedieu G, Deloncle R. Hyperaluminemia in a woman using an aluminum-containing antiperspirant for 4 years. Am J Med. 2004;117(12):956-959.

51. Duty SM, Ackerman RM, Calafat AM, Hauser R. Personal care product use predicts urinary concentrations of some phthalate monoesters. Environ Health Perspect. 2005;113(11):1530-1535.

52. Allmyr M, Adolfsson-Erici M, McLachlan MS, Sandborgh-Englund G. Triclosan in plasma and milk from Swedish nursing mothers and their exposure via personal care products. Sci Total Environ. 2006;372(1):87-93.

53. Klinubol P, Asawanonda P, Wanichwecharungruang SP. Transdermal penetration of UV filters. Skin Pharmacol Physiol. 2008;21(1):23-29.

54. Schlumpf M, Kypke K, Vökt C. Endocrine active UV filters: developmental toxicity and exposure through breast milk. Chimia. 2008;62(5):345-351.

55. Jovanovic ML, McMahon JM, McNett DA, Tobin JM, Plotzke KP. In vitro and in vivo percutaneous absorption of $14 \mathrm{C}$-octamethylcyclotetrasiloxane (14C-D4) and 14C-decamethylcyclopentasiloxane (14C-D5). Regul Toxicol Pharmacol. 2008;50(2):239-248.

56. Reddy MB, Looney RJ, Utell MJ, Plotzke KP, Andersen ME. Modeling of human dermal absorption of octamethylcyclotetrasiloxane (D4) and decamethylcyclopentasiloxane (D5). Toxicol Sci. 2007;99(2):422-431.

57. Hayden CG, Roberts MS, Benson HA. Systemic absorption of sunscreen after topical application. Lancet. 1997;350(9081):863-864.

58. Jiang R, Roberts MS, Collins DM, Benson HA. Absorption of sunscreens across human skin: an evaluation of commercial products for children and adults. Br J Clin Pharmacol. 1999;48(4):635-637. 


\section{Publish your work in this journal}

Clinical, Cosmetic and Investigational Dermatology is an international, peer-reviewed, open access, online journal that focuses on the latest clinical and experimental research in all aspects of skin disease and cosmetic interventions. This journal is included on PubMed. The manuscript management system is completely online and includes a very quick and fair peer-review system, which is all easy to use. Visit http://www.dovepress.com/testimonials.php to read real quotes from published authors

Submit your manuscript here: https://www.dovepress.com/clinical-cosmetic-and-investigational-dermatology-journal 